\title{
Formal Validation of a Deterministic MAC Protocol
}

\author{
KAREN GODARY-DEJEAN, LIRMM, UMSF, CNRS \\ DAVID ANDREU, Demar team, INRIA, LIRMM, UMSF
}

\begin{abstract}
This article deals with the formal validation of STIMAP, a medium access protocol which has been designed to meet the specific requirements of an implantable network-based neuroprosthesis. This article presents the modeling and the validation of its medium access, using model checking on Time Petri Nets. Doing so, we show that existent formal methods and tools are not perfectly suitable for the validation of real systems, especially when some hardware parameters have to be considered. This article then presents how these difficulties have been managed during the modeling and verification phases, and gives the validation results for STIMAP, providing constraints to respect.
\end{abstract}

Categories and Subject Descriptors: C.2.2 [Computer-communication networks]: Network ProtocolsProtocol verification; C.2.5 [Computer-communication networks]: Local and Wide-Area NetworksAccess schemes, Buses; D.2.4 [Software engineering]: Software/Program Verification-Validation

General Terms: Reliability, Verification

Additional Key Words and Phrases: Distributed architecture, Formal validation, MAC determinist protocol, Model checking, Modeling, Timed Petri nets

ACM Reference Format:

Godary-Dejean, K. and Andreu, D. 2012. Formal Validation of a Deterministic MAC Protocol. ACM Trans. Embedd. Comput. Syst. V, N, Article A (January YYYY), 1 pages.

DOI $=10.1145 / 0000000.0000000$ http://doi.acm.org/10.1145/0000000.0000000

THIS ARTICLE WILL BE PUBLISHED SOON...

Received March 2010; revised January 2012; accepted March 2012

Author's address: K. Godary-Dejean and D. Andreu, LIRMM, UMR 5506, 161 rue Ada, 34095 Montpellier Cedex 5 FRANCE.

Permission to make digital or hard copies of part or all of this work for personal or classroom use is granted without fee provided that copies are not made or distributed for profit or commercial advantage and that copies show this notice on the first page or initial screen of a display along with the full citation. Copyrights for components of this work owned by others than ACM must be honored. Abstracting with credit is permitted. To copy otherwise, to republish, to post on servers, to redistribute to lists, or to use any component of this work in other works requires prior specific permission and/or a fee. Permissions may be requested from Publications Dept., ACM, Inc., 2 Penn Plaza, Suite 701, New York, NY 10121-0701 USA, fax +1 (212) 869-0481, or permissions@acm.org.

(c) YYYY ACM 1539-9087/YYYY/01-ARTA $\$ 10.00$

DOI 10.1145/0000000.0000000 http://doi.acm.org/10.1145/0000000.0000000 